\title{
Current Status of Cataract Surgery-A Review of Personal Experience
}

\author{
HUNG CHENG \\ Oxford
}

\begin{abstract}
Summary
One hundred and five eyes treated consecutively over a 5 year period for senile cataract by extracapsular extraction and posterior chamber lens (PC) implantation were compared with 112 consecutive eyes taken from a prospective study which had extracapsular surgery and iridocapsular lens implantation and had been followed from 4 to 7 years. At 1 year the visual acuity of eyes of the two groups were similar but a trend suggests better results in the PC groups. The PC group also had fewer serious complications and less endothelial cell loss.
\end{abstract}

Until the advent of medical treatment to prevent or to reverse cataract, surgery is going to remain the cornerstone of treatment.

In line with the United States of America and Denmark ${ }^{2}$ the increase in demand for cataract surgery in the United Kingdom is reflected by figures both from the Oxford Eye Hospital and nationally. In a decade the throughput in cataract surgery has nearly doubled in Oxford and has increased by 1.4 times nationally in five years. ${ }^{3}$ Some of the increase can certainly be accounted for by the increased use of intraocular lenses (IOL) which has widened the scope of surgery and has increased the available pool of patients.

There is now no absolute contra-indication for lens implantation in the treatment of senile cataract and the age limit is lowering all the time.

It is pertinent to ask the question of how good is the current practice? In the USA, where nearly one million cataract operations are done every year, published figures from the FDA ${ }^{1}$ showed that of 470,000 IOLs that were implanted in a six month period in 1985 to 1986,86 per cent were of the posterior chamber type coupled with extracapsular extraction. Although there are no exact figures, available information suggests a similar trend in the United Kingdom.

With such a large turnover what sort of complications may we be storing up for the future? Considering that posterior chamber lenses have been in use for more than a decade there are few reports on longterm outcome. Only one report has appeared, by Southwick and Olson, ${ }^{4}$ on the longterm results of the Shearing posterior chamber lens where the minimum follow-up was five years. However, there was a major weakness in their study, which could only account for 168 out of an intended pool of 514 patients (approx $33 \%$ ).

To try and increase our understanding of the present situation I have reviewed our own experience knowing that we have good follow-up of our cases even though we do not have large numbers. The purpose of this paper is to compare the short-term follow-up of eyes with posterior chamber lenses and of those with iridocapsular lenses in terms of vision and complications. Information from a prospective study of long duration and no loss of patients to follow-up will also be examined. 


\section{Patients and Method}

A posterior chamber lens group with consecutive eyes treated by the same surgeon and having a minimum follow-up of 6 months were included. The lens used had J-loop haptics made of polypropylene with a $10^{\circ}$ forward angulation. Placement was in the ciliary sulcus by intention and Healon was not used nor were other viscoelastic agents except in one case with partial rupture of the zonule.

The first 74 patients to be operated on with posterior chamber lenses were reviewed by an independent observer and the visual acuity assessed by an ophthalmic optician. It was not logistically possible to do the same with the following 31 patients in that group and their visual acuity and complications were obtained from clinical records.

Comparatively few of the patients with posterior chamber lenses had both pre- and post-operative endothelial cell counts. Where pre-operative cell counts are not available cell loss was taken to be the difference between the operated and unoperated eyes.

Iridocapsular lens group - this group formed the third arm of a randomised controlled trial which was designed to compare three ways of treating cataract - the other two arms of the trial were: (A) intracapsular extraction and (B) intracapsular extraction plus an iris-clip lens implant (Federov 1).

All eyes in this group were seen as part of a structured follow-up in the context of the randomised controlled trial which has already been described $^{5}$ where vision was assessed by an ophthalmic optician and complications recorded by a trained observer who was not the surgeon who had done the operations.

Endothelial cell densities for this group were obtained according to a strict protocol, pre-operatively, at 1 month, 6 months and at yearly intervals.

\section{Results}

Figure 1 shows the most recent visual acuity of the group with posterior chamber lenses. More than 95 per cent of eyes had visual acuity of $6 / 12$ or better and 4 out of 5 of those who failed to get better vision had a disease unrelated to the operation. However, the duration of follow-up varied widely and the range was from 6 months to 5.5 years. To get a more valid comparison the one year visual acuities of the two groups were compared.

Table I shows the total number of eyes in each group with visual acuity at one year. There were 86 eyes with posterior chamber

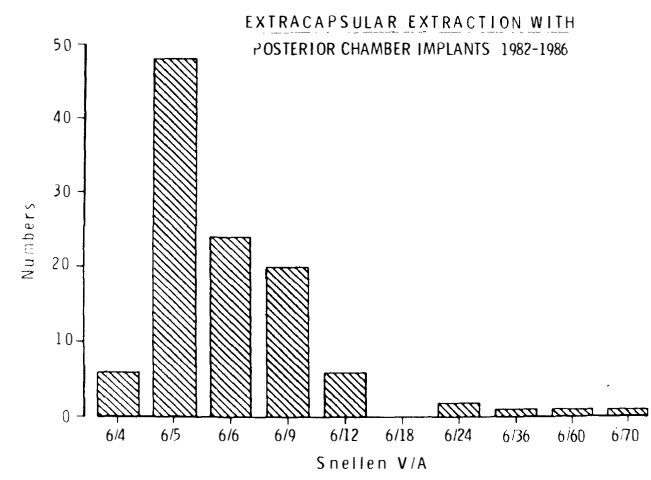

Fig. 1. Snellen VA of 105 eyes treated consecutively for senile cataract by one surgeon with the same style of intraocular lens. Of the 5 eyes failing to achieve 6/12 $V A, 2$ had diabetic retinopathy, 2 had macular degeneration and 1 had capsule opacification

lenses compared with 110 eyes with iridocapsular lenses. Eyes with posterior chamber lenses compared very favourably with those with iridocapsular lenses whether one takes $6 / 12,6 / 6$ or $6 / 5$ as the level of visual acuity for comparison. We know from our longer follow-up of the iridocapsular lens group that there was no significant fall off in visual acuity over a three year period (unpublished data) so that the short-term prospects are good.

At surgery, few complications were encountered by either group but there were 5 cases of vitreous loss in the iridocapsular group (Table II). As the posterior chamber lens group were a later group of patients treated, the improved performance could have been part of the learning process and is not necessarily a result of the type of lens used.

Table I. Comparison of visual acuity at one year for eyes with iridocapsular and posterior chamber lenses

\begin{tabular}{lcc}
\hline & \multicolumn{2}{c}{ Treatment Group } \\
\cline { 2 - 3 }$V A$ & $\begin{array}{c}\text { Iridocapsular } \\
\text { Lens }\end{array}$ & $\begin{array}{c}\text { Posterior Chamber } \\
\text { Lens }\end{array}$ \\
\hline$>6 / 5$ & $36(33)$ & $43(50)$ \\
$>6 / 6$ & $74(67)$ & $63(73)$ \\
$>6 / 12$ & $104(95)$ & $83(97)$ \\
Total eyes & 110 & 86 \\
\hline
\end{tabular}

Number of eyes and (\%) in each treatment group achieving different levels of Snellen visual acuity. 
Table II. Surgical complications

\begin{tabular}{lcc}
\hline $\begin{array}{l}\text { Posterior Chamber } \\
N=105\end{array}$ & $\begin{array}{c}\text { Iridocapsular } \\
N=112\end{array}$ \\
\hline Zonular rupture & 1 & 0 \\
Vitreous loss & 0 & 5 \\
Torn iris & 0 & 1 \\
\hline
\end{tabular}

Complications recorded at operation of the two groups of eyes having extracapsular extraction and two different types of lens implants.

Of the post-operative complications only 'serious' or sight threatening complications were included in Table III. The meaning of 'serious' is arbitrary but an attempt to define it has been made in a previous publication ${ }^{6}$ and the word is used here in that context. Table III shows all the serious complications encountered by either group. As one might expect the two operations and lenses are different in several respects and one would expect some differences in the type of complications.

Table III lists complications encountered up to the 1 year point as well as for the entire period of follow-up (aggregate). The latter was much longer for the group with iridocapsular lenses with a minimum of 4 years compared to a mean of only 15.7 months for the group with posterior chamber lenses. However, for either group, comparing the number of complications collected in the entire period with that accumulated to the 1 year point, there was little tendency for the numbers to increase except for capsule opacification and bullous keratopathy. No eye has yet developed bullous keratopathy in the posterior chamber lens group but it is too early to tell since no eye had developed this complication in the iridocapsular lens group until after the third year of follow-up.

If order to gain more knowledge of this condition we looked at the fate of eyes in the randomised controlled trial ${ }^{5}$ which has a much longer follow-up and no untraced patients. In this prospective study of which the iridocapsular lens group formed a part, we have noted 12 eyes with bullous keratopathy to date out of a total of 333 eyes recruited into the study. The twelve were divided equally between the two treatment groups with lens implants (Table IV); six in eyes with extracapsular extraction and iridocapsular lens implants and six in eyes after intracapsular extraction and insertion of an iris clip lens (Federov I). ${ }^{5}$ The cause of bullous keratopathy is readily apparent in all but one of the eyes with iris-clip lenses but in only two of the eyes with iridocapsular lenses could we identify the cause. Three of the other four eyes with initial cell density near the mean value had small amounts of cell loss after the operation and large losses occurred later in the follow-up for no identifiable reason. Throughout, these 4 eyes were free of complications until the point of corneal decompensation.

Mean cell loss profiles for the group with posterior chamber lenses and iridocapsular lenses are plotted in Figure 2. The mean cell loss at 1 month was much smaller for the posterior chamber lens group and the rate of loss had slowed to normal background levels much sooner than in the iridocapsular lens group. A background loss of 1 per cent per annum was determined by estimating cell loss over a two year period in the unoperated eyes of 103 patients in the prospective study. ${ }^{7}$ Even for the iridocapsular lens group the mean rate of cell loss returned to normal values by the third year of follow-up.

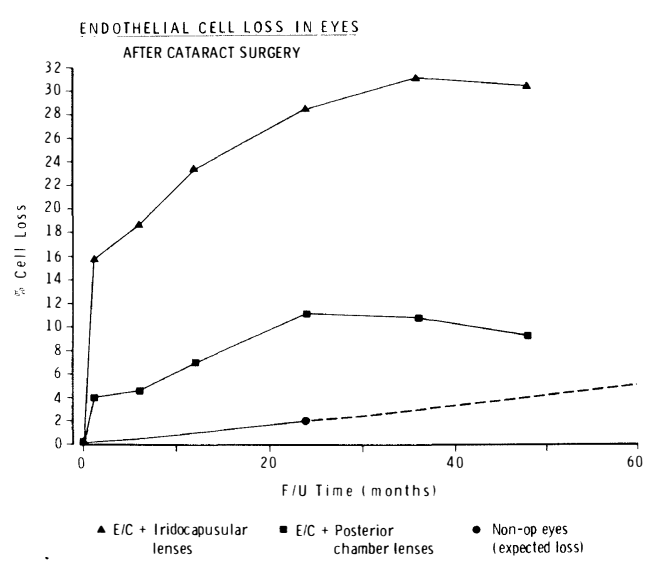

Fig. 2. Endothelial cell loss in eyes after cataract surgery. For information on the number of eyes studied see Table $V$.

Looking at the cell density recorded serially in individual eyes significant numbers of eyes with iridocapsular lenses have suffered cell losses greater than 40 per cent. Thus, 20 per cent $(17 / 86)$ of eyes have suffered a loss of 40 
per cent or greater at one year. In contrast, no eye in the posterior chamber lens group had suffered a 40 per cent cell loss, out of the 53 which had density estimations, even though some eyes had a follow-up period as long as 4 years (Table V).

Table III. Post-operative complications

\begin{tabular}{|c|c|c|c|c|}
\hline \multicolumn{5}{|c|}{ Posterior Chamber Lenses $(P C) v$ Iridocapsular Lenses (IC) } \\
\hline & $\begin{array}{c}P C \\
N=105\end{array}$ & & $\begin{array}{c}I C \\
N=112\end{array}$ & \\
\hline & $1 \mathrm{yr}$ & Agg & $1 \mathrm{yr}$ & Agg \\
\hline Dislocation/sublux & 0 & 0 & 3 & 3 \\
\hline Retinal detachment & 0 & 0 & 2 & 2 \\
\hline Hypopyon & 0 & 0 & 2 & 2 \\
\hline Pupil block & 0 & 0 & 2 & 2 \\
\hline $\mathrm{CMO}$ & 3 & 3 & 14 & 16 \\
\hline Persistent CMO & 0 & 0 & 3 & 3 \\
\hline Capsule opacification & 7 & 11 & 4 & 19 \\
\hline Bullous keratopathy & 0 & 0 & 0 & 6 \\
\hline Mean follow-up time in months & 15.7 & & $>48$ & \\
\hline Range of follow-up time in months & 6 to 60 & & 46 to 90 & \\
\hline
\end{tabular}

Agg = Aggregate and means the entire period of follow-up.

Table IV. Percentage cell loss in patients developing bullous keratopathy

\begin{tabular}{|c|c|c|c|c|c|c|c|c|c|c|c|}
\hline \multirow{2}{*}{$\begin{array}{l}\text { Patient } \\
\text { code }\end{array}$} & \multirow{2}{*}{$\begin{array}{l}\text { Treatment } \\
\text { group }\end{array}$} & \multicolumn{2}{|c|}{ Time post-op } & \multirow[b]{2}{*}{$1 y r$} & \multirow[b]{2}{*}{$2 y r$} & \multirow[b]{2}{*}{$3 y r$} & \multirow[b]{2}{*}{$4 y r$} & \multirow[b]{2}{*}{$5 y r$} & \multirow[b]{2}{*}{$6 y r$} & \multirow[b]{2}{*}{$7 y r$} & \multirow[b]{2}{*}{ Cause of cell loss } \\
\hline & & 1 month & 6 months & & & & & & & & \\
\hline $1-7$ & B & & 29 & 43 & 64 & 68 & deceased & & & & Unknown \\
\hline $1-11$ & $\mathrm{~B}$ & & $\bullet 18$ & $\downarrow 67$ & 74 & 79 & 76 & 77 & 68 & 69 & Implant subluxation \\
\hline $1-18$ & $\mathrm{C}$ & • & $\downarrow 63$ & 72 & 77 & 87 & graft & & & & Operative trauma \\
\hline $1-27$ & $\mathrm{C}$ & $\downarrow 40$ & 48 & 64 & 65 & 80 & $\mathrm{u} / \mathrm{c}$ & graft & & & Unknown \\
\hline $1-30$ & $\mathrm{~B}$ & $\bullet$ & $\downarrow 47$ & 51 & 56 & 78 & 77 & 82 & $\mathrm{u} / \mathrm{c}$ & & $\begin{array}{l}\text { Glaucoma and } \\
\text { hypopyon uveitis } \\
\text { post-op }\end{array}$ \\
\hline $1-71$ & $\mathrm{~B}$ & $\bullet 31$ & $\downarrow 47$ & 78 & 78 & 80 & 88 & $\mathrm{u} / \mathrm{c}$ & & & $\begin{array}{l}\text { Late shallowing of } \\
\text { AC }\end{array}$ \\
\hline $1-87$ & B & $\bullet$ & $\downarrow 44$ & 42 & 62 & 72 & 74 & $\mathrm{u} / \mathrm{c}$ & & & $\begin{array}{l}\text { Decentred lens needs } \\
\text { repositioning }\end{array}$ \\
\hline $1-110$ & B & $\bullet 8$ & 21 & $\downarrow 51$ & 86 & $\mathrm{u} / \mathrm{c}$ & graft & & & & $\begin{array}{l}\text { Hypopyon uveitis } \\
\text { and glaucoma } \\
\text { post-op }\end{array}$ \\
\hline $1-114$ & $\mathrm{C}$ & -5 & 6 & 16 & $\downarrow 37$ & 71 & 84 & & & & Unknown \\
\hline $1-156$ & $\mathrm{C}$ & 16 & 24 & $\downarrow 51$ & 70 & $\mathrm{u} / \mathrm{c}$ & & & & & Unknown \\
\hline $1-170$ & $\mathrm{C}$ & 16 & 19 & $\downarrow 43$ & 75 & 76 & 85 & & & & Unknown \\
\hline $1-271$ & $\mathrm{C}$ & 10 & 24 & $\downarrow 48$ & $\bullet 81$ & $\mathrm{u} / \mathrm{c}$ & & & & & $\begin{array}{l}\text { Intermittent touch } \\
\text { because of iris } \\
\text { adhesions to pedicle }\end{array}$ \\
\hline
\end{tabular}

Serial recordings of percentage cell loss in eyes developing bullous keratopathy in a prospective study.

Treatment group $\mathrm{B}=\mathrm{I} / \mathrm{C}$ extraction with Federov iris-clip lens implant; group $\mathrm{C}=\mathrm{E} / \mathrm{C}$ extraction with iridocapsular lens implant.

$\downarrow \& \bullet$ mark the points when large drop in cell count and complications are noted respectively.

Range of pre-op cell density $=1740-3106 / \mathrm{mm}^{2}$

Mean $=2476 / \mathrm{mm}$. 
Table V. Cell loss after cataract surgery. Number of eyes studied

\begin{tabular}{lccrcrrr}
\hline & & \multicolumn{5}{c}{ Time in years } \\
\cline { 3 - 8 } Type of Eye & $\begin{array}{l}\text { Total } \\
\text { eyes }\end{array}$ & $1 / 12$ & $6 / 12$ & 1 & 2 & 3 & 4 \\
\hline Iridocapsular Lens & 108 & 91 & 105 & 104 & 99 & 92 & 59 \\
Posterior Chamber & 53 & 15 & 24 & 25 & 21 & 16 & 7 \\
Non-operated & 103 & & & & 103 & & \\
\hline
\end{tabular}

Cell loss after cataract surgery. Number of eyes studied at each time point. All eyes with iridocapsular lenses and non-operated eyes had counts at time zero. Only 22 eyes with posterior chamber lenses had pre-operative cell counts. See 'methods' in text for explanation.

\section{Discussion}

The two groups of eyes are not strictly comparable because one group was studied prospectively while the other comprised patients looked at both prospectively and retrospectively. Furthermore the two groups of eyes were not treated concurrently, although they overlapped in time. The posterior chamber lens group might have had better results by being a later group and had benefited through a learning process. However, the posterior chamber lens group comprised consecutive patients and the only eyes excluded were those with glaucoma who had combined glaucoma and cataract surgery. Therefore, there is no conscious selection bias.

Allowing for these differences the visual acuity of both groups were comparable to the best reports of visual outcome in cataract surgery and suggest that the short-term visual results are good irrespective of the type of implant. As these patients tend to be elderly (mean age $=72$ years) one can expect a drop in visual acuity with time but, in our prospective study, eyes with iridocapsular lenses tend to keep the same level of vision over a three year period with no significant reduction in this interval (unpublished data).

The small number of complications recorded is also encouraging and if the iridocapsular lens group is a guide, then complications should not increase significantly with time in the posterior chamber lens group, particularly since the design and location of the implant are believed to be improvements.

However, two complications clearly did increase with time and they are capsule opacification and bullous keratopathy.
Capsule opacities can be treated surgically by capsulotomy, a relatively safe and simple procedure using the YAG laser. Because of this there is a tendency to do this sooner rather than later which may have accounted for the slight increase in the proportion of cases treated in the posterior chamber lens group. This complication does not present a real problem.

Bullous keratopathy however, is a serious complication which is known to increase with time and has poor visual prognosis. Very few reports claim even a $50 \%$ recovery of $6 / 12$ visual acuity after corneal graft and many much less. ${ }^{8}$ The fact that 4 out of 6 of our eyes after extracapsular extraction and iridocapsular lens implant developed bullous keratopathy for no apparent reason is worrying. While the lens type is different both iridocapsular and posterior lens implantation share the initial procedure of extracapsular extraction which could conceivably have weakened the endothelial cells. ${ }^{9} \mathrm{~A}$ redeeming feature is that the mean cell loss of our patients is much less after posterior chamber lens implantation and that there is no tendency for accelerated cell loss or for individuals to lose large amounts. However, the numbers we looked at are small and a longer follow-up of a larger sample is required to form firm opinions.

Meanwhile the available evidence suggests that the procedure is not only safe but yields good results for senile cataract. What we lack still is a good indicator of a safe lower age limit.

I am grateful to all the participants of the Cataract Management Study at Oxford for allowing me access to the data of the randomised controlled 
trial, to Linda Wood for data collection and analysis, Drs Keith Bates and Sally MacLennan for independent review of some of the patients, Ivy Samuel for secretarial help and Don Barbour for photographic work.

This work is supported in part by NIH grant No: EY02677-08.

\section{References}

'Stark WJ, Whitney CE, Chandler JW, Worthen DM: Trends in intraocular lens implantation in the United States; Arch Ophthalmol 1986, 104: 1769-70.

${ }^{2}$ Bernth-Petersen P: Cataract surgery, outcome assessments and epidemiological aspects. Acta Ophthalmol 1985, 63: (suppl 174) 27-37.

3 OPCS Monitor: Hospital In-patient Enquiry (England) Trends 1979-1984. Ref MB4 86/1.

${ }^{4}$ Southwick PC and Olson RJ: Shearing posterior chamber intraocular lenses: five year postoperative results. J Am Intraocular Lens Implant Soc 1984, 10: 318-23.

5 OCTET I: Cataract surgery: Interim results and complications of a randomised controlled trial Br J Ophthalmol 1986, 70: 402-10.

${ }^{6}$ OCTET II: Use of a grading system in the valuation of complications in a randomised controlled trial on cataract surgery. BrJ Ophthalmol 1986, 70: 411-4.

${ }^{7}$ Cheng H, Jacobs PM, McPherson K, Noble MJ; Precision of cell density estimates and endothelial cell loss with age. Arch Ophthalmol 1985. 103: $1478-81$.

${ }^{8}$ Schanzlin DJ, Robin JB, Gomez DS, Gindi JJ, Smith RE: Results of penetrating keratoplasty for aphakic and pseudophakic bullous keratopathy. Am J Ophthalmol 1984, 98: 302-12.

${ }^{9}$ Edelhauser HF, Van Horn DL, Hyndink RA, Schultz RO: Intraocular irrigating solutions. Arch Ophthalmol 1975, 93: 648-57. 